\title{
The LupusQoL and Associations with Demographics and Clinical Measurements in Patients with Systemic Lupus Erythematosus
}

\author{
KATHLEEN MCELHONE, MADHURA CASTELINO, JANICE ABBOTT, IAN N. BRUCE, YASMEEN AHMAD, \\ JOANNA SHELMERDINE, KATE PEERS, DAVID ISENBERG, ADA FERENKEH-KOROMA, BRIDGET GRIFFITHS, \\ MOHAMMED AKIL, PETER MADDISON, CAROLINE GORDON, and LEE-SUAN TEH
}

\begin{abstract}
Objective. Having developed and validated a disease-specific health-related quality of life (HRQOL) measure for patients with systemic lupus erythematosus (SLE), the LupusQoL, we determined its relationship to demographic and clinical measurements in a group of patients with SLE.

Methods. A group of 322 outpatients completed the LupusQoL. Demographic (age, sex, marital status, ethnicity) and clinical variables (disease duration, disease activity, damage) were recorded. Associations between the 8 LupusQoL domains and age, disease duration, disease activity, and damage were explored using Spearman's correlation coefficients. Differences in LupusQoL scores were examined for sex and marital status using the Mann-Whitney U test. Ethnic groups were compared using ANOVA.

Results. All domains of LupusQoL were impaired, with fatigue (56.3) being the worst affected and body image (80.0) the least. The correlations between the LupusQoL domain scores and age $(\mathrm{r}=$ -0.01 to -0.22$)$ and disease duration $(r=0$ to 0.16$)$ were absent or weak. Similarly, there were no significant differences in the LupusQoL scores regarding sex, marital status, or the 3 main ethnic groups (Black-Caribbean, Asian, White). Although there were statistically significant correlations between the scores of the LupusQoL domains and some scores of the British Isles Lupus Assessment Group index ( $\mathrm{r}=-0.22$ to 0.09 ) and the Systemic Lupus International Collaborating Clinics/American College of Rheumatology Damage Index ( $r=-0.29$ to 0.21$)$, these were weak.

Conclusion. HRQOL was impaired in this cohort of outpatients with SLE as assessed by the validated lupus-specific LupusQoL. There were no clinically important associations between the 8 domains of the LupusQoL and clinical or demographic variables in this group of patients. Thus, the LupusQoL is a relatively independent outcome measure in patients with SLE. (First Release September 1 2010; J Rheumatol 2010;37:2273-9; doi:10.3899/jrheum.091277)
\end{abstract}

Key Indexing Terms: LUPUSQOL

\section{SYSTEMIC LUPUS ERYTHEMATOSUS}

From the Department of Rheumatology, Royal Blackburn Hospital, Blackburn; the Arthritis Research UK Epidemiology Unit, School of Translational Medicine, The University of Manchester; the Kellgren Centre for Rheumatology, Central Manchester Foundation Trust, Manchester; University of Birmingham, Birmingham; Middlesex Hospital, London; Freeman Hospital, Newcastle; Hallamshire Hospital, Sheffield; Ysbyty Gwynedd, Bangor; and the Faculty of Health, University of Central Lancashire, Preston, UK.

Partially supported by Lupus UK and the former North West National Health Service Executive Research and Development Directorate, and the Arthritis Research Campaign.

K. McElhone, PhD; M. Castelino, MRCP; L-S. Teh, MD, FRCP, Department of Rheumatology, Royal Blackburn Hospital; J. Abbott, PhD, Faculty of Health, University of Central Lancashire; I.N. Bruce, MD, FRCP; Y. Ahmad, PhD, FRCP, Arthritis Research UK Epidemiology Unit, School of Translational Medicine, University of Manchester;

$J$. Shelmerdine, RN, Kellgren Centre for Rheumatology, Central Manchester Foundation Trust; K. Peers, RGN, MSc; C. Gordon, MD, $F R C P$, University of Birmingham; D. Isenberg, $M D, F R C P$;

A. Ferenkeh-Koroma, BSc, Middlesex Hospital; B. Griffiths, MD, FRCP,

Freeman Hospital; M. Akil, MD, FRCP, Hallamshire Hospital;

P. Maddison, MD, FRCP, Ysbyty Gwynedd.

Address correspondence to Dr. L-S. Teh, Department of Rheumatology, Administration Block, Level 1, Royal Blackburn Hospital, Haslingden Road, Blackburn BB2 3HH, UK. E-mail: lsteh@btinternet.com

Accepted for publication June 24, 2010.
Systemic lupus erythematosus (SLE) is a major autoimmune rheumatic disease that is more common in young women during the childbearing years and those of Chinese, Asian, and African American/Caribbean origin ${ }^{1,2,3}$. The disease varies in its clinical manifestations and severity between individuals, and the course of the disease for most patients is characterized by unpredictable relapses and remissions ${ }^{4}$. The improved survival of patients with SLE in the last 40 years ${ }^{5}$ requires measuring the effect of the disease and/or treatment on the patients' day-to-day living, i.e., health-related quality of life (HRQOL), in the management of patients, audits, clinical trials, and longterm observational studies.

The LupusQoL is a recently developed and validated disease-specific HRQOL measure for adults with $\mathrm{SLE}^{6}$. It consists of 8 domains: physical health, pain, planning, body image, burden to others, intimate relationships, emotional health, and fatigue. The LupusQoL is a patient-derived disease-specific HRQOL measure that contains items more relevant to patients with SLE when compared to the generic 
Medical Outcomes Study Short-Form 36 (SF-36) questionnaire ${ }^{6}$. It has been shown to have good internal reliability (Cronbach's $\alpha 0.88$ to 0.95 ), good test-retest reliability ( $\mathrm{r}=$ 0.72 to 0.93 ), and good concurrent validity with the comparable domains of the SF-36 ( $r=0.71$ to 0.79$)$. It has acceptable ceiling effects and minimal floor effects. Scoring of the LupusQoL is such that 0 represents worst health and 100 represents best health ${ }^{6}$ for each domain. However, the sensitivity to change (responsiveness) and the minimal clinically important difference of the LupusQoL are still not determined, although those studies are currently under way.

HRQOL studies in SLE usually employ the generic measure, the SF-36, which has been shown to be independent of age, disease duration, disease activity, and damage ${ }^{7}$. As the LupusQoL is a newly developed disease-specific HRQOL measure, our primary aim was to examine whether this independence is also true for the LupusQoL. Our secondary aims were to describe HRQOL in a cohort of patients with SLE using the LupusQoL and to determine if there were any correlations between the LupusQoL domain scores and other demographic measures (sex, marital status, ethnicity).

\section{MATERIALS AND METHODS}

The study was granted Multi-centre Research Ethics Committee approval and participants from the collaborating centers gave written informed consent. The collaborating rheumatology units were UK centers with an interest in SLE as part of the British Isles Lupus Assessment Group (BILAG): Bangor, Birmingham, Blackburn, University College London, Manchester, Newcastle, and Sheffield. All patients fulfilled 4 or more of the revised American College of Rheumatology (ACR) criteria for $\mathrm{SLE}^{8,9}$.

The study design was cross-sectional and patients were approached during their routine rheumatology outpatient attendance. Those who consented to take part in the study either completed the LupusQoL at the outpatient clinic or took it home to complete and were instructed to return it by post within a week. Demographic (age, sex, ethnic group, marital status) and clinical information (duration of SLE, disease activity, damage) were recorded at the time of consent. Ethnicity was defined in accord with the UK Office of National Statistics ${ }^{10}$ and the main groups included White (British, Irish), Asian (Indian, Pakistani, Bangladeshi), Black (Black Caribbean, Black African), Mixed (White and Black Caribbean, White and Black African, White and Asian), Chinese, or others. The marital status data collected were as follows: married/living with partners, single, widowed, separated/divorced, and for statistical analysis, the patients were divided into 2 groups. Group 1 included those assumed to be not living with spouses or partners (single, widowed, separated/divorced) and Group 2 included those married or living with partners.

Disease activity was measured by the BILAG index ${ }^{11,12}$ and damage by the Systemic Lupus International Collaborating Clinics ACR-Damage Index (SLICC ACR-DI) ${ }^{13}$, both of which were assessed on the date of consent. The BILAG index consists of 86 items (symptoms, signs, and laboratory results) that were scored as absent or present, and if present, whether that item was new, worse, the same, or better over the previous 4 weeks. These items are 8 organ systems (general, mucocutaneous, neurological, musculoskeletal, cardiovascular and respiratory, vasculitis, renal, and hematological), which are then each scored on a 5-point ordinal scale (A to E) based on the principles of the "physician's intention to treat." Although it was not the original intention of the BILAG to produce an overall score, for some types of analysis it became necessary to do so, and after some discussion a scoring system was developed: $\mathrm{A}=9, \mathrm{~B}=3, \mathrm{C}=1, \mathrm{D}$ and $\mathrm{E}=$
$0^{14}$. The SLICC ACR-DI assesses damage over 12 organs or systems: ocular (range $0-2)$, neuropsychiatric $(0-6)$, renal (0-3), pulmonary $(0-5)$, cardiovascular (0-6), peripheral vascular $(0-5)$, gastrointestinal (0-6), musculoskeletal (0-7), skin (0-2), gonadal (0-1), endocrine damage (0-1), and malignancy (0-2). The maximum possible total score is 48 .

HRQOL using the LupusQoL was also described and the associations between the 8 domains of the LupusQoL and demographic and other clinical measures in these patients were explored.

Statistical methods. Patient data were summarized using the following descriptive statistics: means (SD), medians [interquartile ranges (IQR)], and/or frequency counts. The continuous variables of age and disease duration and the median scores of disease activity and damage for the different organ systems were correlated with the 8 domains of the LupusQoL using the Spearman's $r$ correlation coefficient tests. $P$ values $\leq 0.01$ were taken as significant to allow for multiple testing. Correlation $\mathrm{r}$ values $>0.8$ were considered very strong; 0.6 to 0.8 , strong; 0.4 to 0.6 , moderate; 0.2 to 0.4 , weak; and $<0.2$, absent. Mann-Whitney $\mathrm{U}$ tests were used to compare HRQOL between the 2 groups of sex and marital status. The Kruskal-Wallis one-way ANOVA with Scheffe's posthoc analyses (to account for multiple testing) was employed to compare the LupusQoL domains for the 3 ethnic groups.

\section{RESULTS}

Patient characteristics. Out of the 398 outpatients who were asked to participate in the study, 391 patients consented, and of those, 322 patients completed the LupusQoL questionnaire, giving a response rate of $81 \%$. The majority of patients completed the LupusQoL on the day of the clinic visit and the remainder completed the questionnaire at home and returned it, as instructed, within a week of the clinic visit. The demographic and clinical data of the patients who consented were collected on the day of the clinic visit. The patient characteristics are summarized in Table 1.

Description of HRQOL for the whole group of patients. HRQOL was impaired but differentially across the domains in these patients with SLE (Table 2). The full spectrum of response was seen for all domains ( 0 representing worst health and 100 , best health). In this population, the body image domain (median 80.0) was the least affected domain, while fatigue was the worst affected (median 56.3). The domains of physical health and burden to others were also impaired (medians 65.6 and 66.7, respectively) in these patients.

The relationship between HRQOL and demographic and clinical features. Table 2 shows the Spearman's r correlation coefficient between age and disease duration and the domains of LupusQoL. There were weak correlations between age and the domains of physical health, intimate relationships, and emotional health $(-0.21,-0.22,+0.16$, respectively), and between disease duration and the domain of emotional health $(+0.16)$, which were statistically significant $(\mathrm{p}<0.01)$.

Two hundred fifty-seven women and 19 men completed the LupusQoL questionnaire. No statistically significant differences were found between men and women. There were also no statistically significant differences between Group 1 $(\mathrm{n}=100)$ and Group $2(\mathrm{n}=154)$ with regard to marital status.

Table 3 shows the median (IQR) of the LupusQoL scores 
Table 1. Patient characteristics. Number given with each characteristic indicates the number of patients who answered that question. Values are percentages unless otherwise indicated.

\begin{tabular}{|c|c|}
\hline \multicolumn{2}{|l|}{ Characteristic } \\
\hline No. patients & 322 \\
\hline Sex & 286 \\
\hline Women & 257 \\
\hline Men & 19 \\
\hline Data missing & 10 \\
\hline Age, yrs & 283 \\
\hline mean (SD) & $45.0(13.4)$ \\
\hline Disease duration, yrs & 273 \\
\hline mean $(\mathrm{SD})$ & $10.5(8.6)$ \\
\hline Marital status, n & 254 \\
\hline Married/living with partner & 61 \\
\hline Single & 30 \\
\hline Widowed & 4 \\
\hline Separated/divorced & 6 \\
\hline Ethnic distribution, $\mathrm{n}$ & 279 \\
\hline White (British, Irish) & 74 \\
\hline Black (Caribbean, African) & 12 \\
\hline Asian (Indian, Pakistani, Bangladeshi) & 10 \\
\hline Chinese & 3 \\
\hline Mixed/others & 1 \\
\hline Clinical characteristics (ACR criteria), $\mathrm{n}$ & 284 \\
\hline Malar rash & 42 \\
\hline Photosensitivity rash & 45 \\
\hline Discoid rash & 18 \\
\hline Mouth ulcers & 43 \\
\hline Arthritis/arthralgia & 90 \\
\hline Serositis & 37 \\
\hline Renal disease & 21 \\
\hline Central nervous system disease & 13 \\
\hline Hematological disease & 69 \\
\hline Positive antinuclear antibodies & 92 \\
\hline Presence of anti-dsDNA, Sm, or phospholipid antibodies & 72 \\
\hline BILAG Index, n & 282 \\
\hline A score in any system & 7 \\
\hline Score no more than B in any system & 50 \\
\hline Score no more than $\mathrm{C}$ in any system & 36 \\
\hline Score of D and/or E in all systems & 7 \\
\hline SLICC ACR-DI score, $\mathrm{n}$ & 274 \\
\hline mean $(\mathrm{SD})$ & $0.75(1.25)$ \\
\hline 0 (no accumulated damage) & 60 \\
\hline 1 & 20 \\
\hline 2 & 10 \\
\hline 3 or more & 10 \\
\hline
\end{tabular}

ACR: American College of Rheumatology; BILAG: British Isles Lupus Assessment Group; SLICC: Systemic Lupus International Collaborating Clinics; ACR-DI: ACR Damage Index.

for the 3 main ethnic groups: Black Caribbean, Asian, and White patients. A difference was observed between the groups for the intimate relationships domain of the LupusQoL, with Black Caribbean patients having the highest median value (better health) compared to Whites $(\mathrm{p}<$ 0.04). The Black Caribbean patients were younger (median age 38 yrs) compared to White patients (median age $46 \mathrm{yrs}$ ), and ANCOVA was undertaken with age as the covariate. Age was found to account for the difference between the ethnic groups $(\mathrm{p}<0.004)$.
Disease activity and damage. Complete data for all systems of the BILAG index and SLICC ACR-DI data were available for 269 and 262 patients, respectively. Tables 4 and 5 present the correlations between each domain of the LupusQoL and the 8 organ systems of the BILAG index and the 12 organ systems of the SLICC ACR-DI, respectively. The correlations were all weak. However, correlations between some domains of the LupusQoL and (1) the general systemic features and the musculoskeletal systems of the BILAG ( $\mathrm{r}$ from -0.16 to -0.22 ) as well as (2) the ocular, renal, and pulmonary systems ( $\mathrm{r}$ from -0.26 to -0.29 ) of the SLICC ACR-DI were statistically significant $(\mathrm{p}<0.01)$.

\section{DISCUSSION}

Our study found that HRQOL in patients with SLE as measured by the LupusQoL was impaired in all domains, especially those of fatigue, physical health, and burden to others. The domain most impaired was fatigue, consistent with other studies $^{15,16,17,18}$. Fibromyalgia may have contributed to fatigue but we did not assess our patients for fibromyalgia, which may be a limitation of our study. However, a study has shown a low prevalence (10\%) of fibromyalgia in the UK SLE population ${ }^{19}$, so it is unlikely to have contributed significantly to the high level of fatigue in our patients. Physical health has also been documented to be poor in patients with SLE in studies employing generic measures such as the SF-20 20,21 and the SF- $36^{22,23,24,25,26}$. The patients also perceive that having SLE places a significant burden on others close to them in both physical and psychological terms. Burden to others is a domain that has not been assessed in other HRQOL measures, and if our finding is confirmed, it may warrant specific intervention strategies.

Body image was the least impaired domain in this group of patients and this was at odds with the emphasis placed on it by patients during the semistructured interviews conducted for the item generation of the LupusQoL measure ${ }^{6}$. The literature is sparse regarding body image in patients with SLE and it has been reported to be worse in SLE than in normal controls or people with rheumatoid arthritis ${ }^{27}$. When patients were subclassified into those with active scores (A or $\mathrm{B}$ ) or inactive scores $(\mathrm{C}, \mathrm{D}$, or $\mathrm{E})$ in the mucocutaneous system of the BILAG index, the median body image scores were significantly lower (poorer) in the active disease group ( $p<0.05$, data not shown). The number of patients with skin damage on the SLICC ACR-DI was small $(\mathrm{n}=11)$ and thus statistical analysis was not undertaken. If the patients were subgrouped into ever having any skin involvement (whether currently active and with or without with skin damage), the body image median scores were not statistically different between the patients with and those without cutaneous involvement (data not shown). This emphasizes the difficulty in defining the concept of body image ${ }^{28}$ and underscores that "body image" is a complex term that encompasses more than SLE-related skin rashes. 
Table 2. LupusQoL scores and correlations between domains and age and disease duration. Numbers indicate number of patients who answered that question.

\begin{tabular}{lccc}
\hline LupusQoL Domains & $\begin{array}{c}\text { Median LupusQoL } \\
\text { (IQR) }\end{array}$ & $\begin{array}{c}\text { Spearman r Correlation } \\
\text { with Age }\end{array}$ & $\begin{array}{c}\text { Spearman r Correlation } \\
\text { with Disease Duration }\end{array}$ \\
\hline Physical health, $\mathrm{n}=315$ & $65.6(40.6$ to 81.3$)$ & $-0.21^{*}$ & 0.06 \\
Pain, $\mathrm{n}=318$ & $75.0(41.7$ to 83.3$)$ & -0.09 & 0.03 \\
Planning, $\mathrm{n}=319$ & $75.0(50.0$ to 91.7$)$ & -0.01 & 0.02 \\
Intimate relationships, $\mathrm{n}=295$ & $75.0(37.5$ to 87.5$)$ & $-0.22^{*}$ & 0.00 \\
Burden to others, $\mathrm{n}=322$ & $66.7(41.7$ to 83.3$)$ & 0.13 & 0.13 \\
Emotional health, $\mathrm{n}=318$ & $75.0(62.5$ to 87.5$)$ & $0.16^{*}$ & $0.16^{*}$ \\
Body image, $\mathrm{n}=312$ & $80.0(55.0$ to 95.0$)$ & -0.07 & 0.07 \\
Fatigue, $\mathrm{n}=321$ & $56.3(32.3$ to 68.8$)$ & & 0.05 \\
\hline
\end{tabular}

$* \mathrm{p}<0.01$. LupusQoL: lupus quality of life questionnaire; IQR: interquartile range.

Table 3. LupusQoL scores for 3 ethnic groups. All data are median (IQR).

\begin{tabular}{lccc}
\hline LupusQoL Domains & Black Caribbean, $\mathrm{n}=34$ & Asian, $\mathrm{n}=27$ & White, $\mathrm{n}=206$ \\
\hline Physical health & $65.6(42.2$ to 89$)$ & $71.9(43.8$ to 84.4$)$ & $62.5(40.6$ to 81.3$)$ \\
Pain & $66.7(33.3$ to 100.0$)$ & $75.0(58.3$ to 83.3$)$ & $75.0(41.7$ to 83.3$)$ \\
Planning & $75.0(33.3$ to 100.0$)$ & $75.0(41.7$ to 95.8$)$ & $75.0(50.0$ to 91.7$)$ \\
Intimate relationships & $87.5(62.5 \text { to } 100.0)^{*}$ & $75.0(43.8$ to 100.0$)$ & $75.0(37.5$ to 87.5$)$ \\
Burden to others & $75.0(25.0$ to 83.3$)$ & $58.3(37.5$ to 79.2$)$ & $66.7(41.7$ to 75.0$)$ \\
Emotional health & $75.0(45.8$ to 87.5$)$ & $75.0(60.4$ to 85.4$)$ & $79.2(66.7$ to 87.5$)$ \\
Body image & $72.5(45.0$ to 90.0$)$ & $80.0(45.0$ to 90.0$)$ & $80.0(55.0$ to 95.0$)$ \\
Fatigue & $56.3(37.5$ to 81.3$)$ & $56.3(37.5$ to 81.3$)$ & $56.3(31.3$ to 68.8$)$ \\
\hline
\end{tabular}

$* \mathrm{p}<0.04$ comparing Black Caribbean to White patients. LupusQoL: lupus quality of life questionnaire; IQR: interquartile range.

Table 4. Correlation between LupusQoL scores and disease activity assessed by BILAG index in the different organ systems.

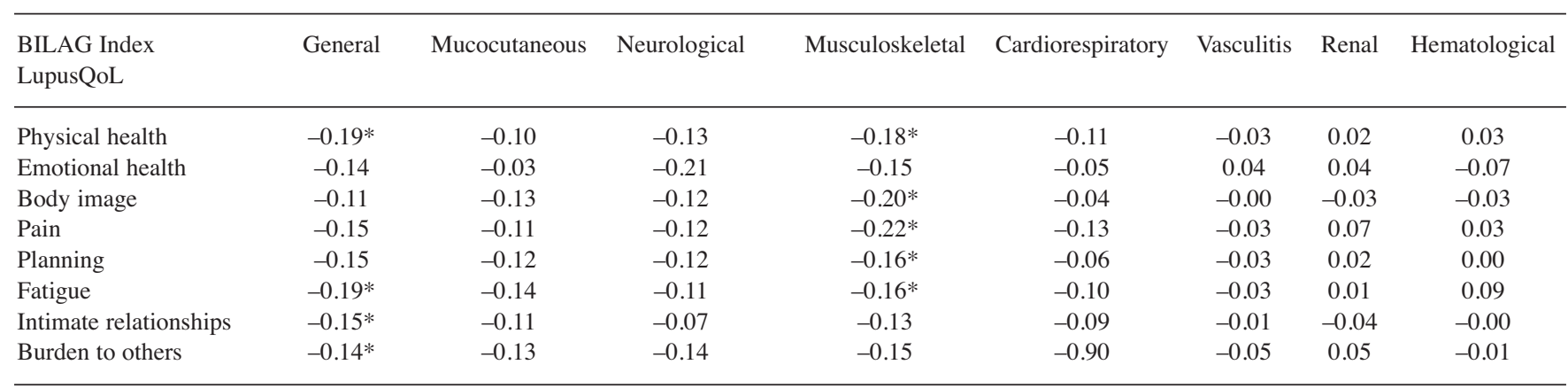

$* \mathrm{p}<0.01$. LupusQoL: lupus quality of life questionnaire; BILAG: British isles Lupus Assessment Group index.

In our study, older age was associated with worse physical health and intimate relationships even though the associations were weak and unlikely to be clinically important. In terms of physical health, the findings were consistent with some studies $22,24,25,29,30,31,32,33,34,35$ but not others, where there was no association reported between age and poorer physical health $21,36,37,38$. It would seem logical that older patients may have poorer physical health, because patients with longer disease duration have greater damage ${ }^{39}$, including more degenerative joint disease, which damages physical health. Longer disease duration was found to be associated with better emotional health in the LupusQoL, but again this was unlikely to be clinically relevant. The literature findings were varied: some investigators reported no significant association between the two $21,25,32,37$; others found that longer disease duration associated to better physical health ${ }^{40}$, HRQOL $(\mathrm{SF}-36)^{38}$, mental health ${ }^{22,35}$, or role emotional $^{30}$; and one reported the association of disease duration with worse physical health ${ }^{29}$. These discrepancies may be due to many reasons including demographic and disease-related differences between different cohorts.

The effect of gender on HRQOL has been examined in only 3 studies $^{35,38,40}$, and like our study, those found no differences between the sexes in terms of HRQOL. For marital 
Table 5. Correlations between LupusQoL scores and damage as assessed by SLICC ACR-DI in the different organ systems.

\begin{tabular}{|c|c|c|c|c|c|c|c|c|c|c|c|c|c|}
\hline $\begin{array}{l}\text { SLICC } \\
\text { ACR-DI } \\
\text { LupusQoL }\end{array}$ & $\begin{array}{r}\text { Ocular } \\
p\end{array}$ & $\begin{array}{l}\text { Neuro- } \\
\text { sychiatric }\end{array}$ & Renal & Pulmonary & $\begin{array}{l}\text { Cardio- } \\
\text { vascular }\end{array}$ & $\begin{array}{c}\text { Peripheral } \\
\text { vascular }\end{array}$ & $\begin{array}{c}\text { Gastro- } \\
\text { intestinal }\end{array}$ & $\begin{array}{l}\text { Musculo- } \\
\text { skeletal }\end{array}$ & Skin & $\begin{array}{c}\text { Premature } \\
\text { Gonadal } \\
\text { Failure }\end{array}$ & $\begin{array}{l}\text { Diabetes } \\
\text { Mellitus }\end{array}$ & Malignancy & $\begin{array}{l}\text { Total } \\
\text { SDI } \\
\text { Score }\end{array}$ \\
\hline Emotional health & -0.16 & -0.04 & 0.17 & -0.13 & 0.10 & 0.00 & -0.10 & -0.08 & -0.11 & 0.02 & -0.01 & -0.06 & -0.06 \\
\hline Body image & -0.19 & -0.10 & 0.12 & -0.17 & 0.11 & 0.00 & 0.11 & -0.12 & -0.17 & 0.14 & -0.01 & -0.04 & -0.07 \\
\hline Pain & $-0.29 *$ & -0.13 & -0.23 & $-0.26^{*}$ & -0.02 & -0.05 & -0.15 & -0.05 & -0.07 & 0.14 & -0.08 & -0.14 & $-0.20 *$ \\
\hline Intimate relationship & $\mathrm{os}-0.26^{*}$ & -0.18 & 0.15 & -0.22 & -0.05 & -0.07 & -0.09 & -0.06 & 0.09 & 0.03 & 0.11 & -0.12 & -0.10 \\
\hline Burden to others & -0.19 & -0.03 & 0.21 & -0.15 & 0.09 & -0.01 & -0.01 & -0.05 & 0.09 & -0.02 & -0.01 & -0.05 & -0.10 \\
\hline
\end{tabular}

$* \mathrm{p}<0.01$. LupusQoL: lupus quality of life questionnaire; SLICC: Systemic Lupus International Collaborating Clinics; ACR-DI: American College of Rheumatology-Damage Index; SDI: SLICC/ACR DI.

status, patients were divided into 2 groups and HRQOL was similar in both. Two studies 36,40 reported no differences in HRQOL involving marital status; one reported that marriage improved social functioning ${ }^{38}$ and another that those who lived alone had better HRQOL than those who did not live alone $^{35}$. However, the way we subdivided our groups and the assumptions we made about patients who were "living alone" could be erroneous and are potential limitations of our study. Further studies are needed with groups carefully defined from the onset.

Comparing the HRQOL scores in the ethnic groups, there were some differences in 2 of the LupusQoL domains. Black Caribbean patients were found to have better intimate relationships compared to White and Asian patients, but this was because of their younger age rather than their ethnicity. There were also statistically significant differences between Whites and Black Caribbeans in terms of age and marital status, Whites being older and more likely to be married (data not shown). Perhaps older age and being married reduce the need for sexual intimacy as a means of maintaining the partnership; this is supported by another study ${ }^{41}$ and may explain some of the ethnic differences in the intimate relationship domain. Although not statistically significant, the different levels of HRQOL between Black Caribbeans and Asians in terms of the "burden to others" domain may be clinically important. This HRQOL domain has not been explored in SLE populations. A UK study ${ }^{42}$ in patients with endstage renal disease reported that Asian patients perceive kidney disease as a social burden even after a successful kidney transplant. Ethnic differences in HRQOL have been examined by only a few authors, possibly because most study populations consisted of predominantly 1 ethnic group, usually Whites, in studies conducted in the West (Europe and the United States), and Chinese patients in studies conducted in Singapore. The relationship between ethnicity and HRQOL deserves further study and may be modulated by clinical status, socioeconomic factors such as poverty and access to medical services ${ }^{35,43}$, and patient factors such as their beliefs in medicines and disease ${ }^{44}$. In our study, socioeconomic status of the patients was not collected and therefore could not be analyzed, but in the UK, there is less association between ethnic minorities and poor socioeconomic status than in the United States ${ }^{1}$.

In our study, $7 \%$ of patients had high disease activity as assessed by the BILAG index (A scores), 7\% had no disease activity ( $\mathrm{D}$ or $\mathrm{E}$ scores only), and the majority of patients had moderate or mild disease activity (scores no higher than $\mathrm{B}$ or $\mathrm{C}$ ), and this is similar to other studies ${ }^{45}$. The BILAG index assessments were carried out at a clinic and most patients completed the LupusQoL at that time. The remainder completed the questionnaire at home and returned it within 1 week, allowing appropriate correlation of their LupusQoL responses to the BILAG index assessments. The small number of patients completing the LupusQoL at home worked against meaningful comparison with those who completed the questionnaire at a clinic. Sixty percent of patients had no damage as assessed by the SLICC ACR-DI, and this is compatible with an outpatient group of patients with SLE. Recent UK studies also show low levels of damage, a condition probably related to a number of factors including diagnosis of milder cases, more aggressive treatment of SLE, and disease duration. In the study by Chambers, et $a l^{39}, 67 \%$ of patients had no damage at 5 years, dropping to $49 \%$ at 10 years. Most of our patients had disease duration $<10$ years, with a median of 8 years (IQR 4 to $16 \mathrm{yrs}$ ). So the figure of $60 \%$ of patients without damage is plausible. In addition, many of the data in the literature are based on data from university teaching hospitals, which are tertiary referral centers treating patients with more severe disease, while our group of patients included those followed up at district general hospitals. Studies of patients with SLE in the United States may also show a higher level of damage in these patients compared to patients with SLE in the UK, where there is universal access to healthcare and education.

In our study, we found that active disease in some systems of the BILAG index and damage in some organs of the SLICC ACR-DI were associated with impairment in some 
domains of the LupusQoL. It is perhaps not surprising that the presence of general constitutional symptoms was related to impaired domains of physical health and fatigue, especially as there is an item measuring fatigue in that system. Activity in the musculoskeletal system may alter the patients' perceptions of the physical health, body image, pain, and fatigue domains. Overall damage was, not surprisingly, associated with poorer physical health, pain, and planning. More surprisingly, damage in the ocular system of the SLICC ACR-DI was significantly correlated to the physical health, pain, planning, and intimate relationship domains. Ocular damage in SLE is most commonly due to cataracts and is likely to be a marker of steroid therapy prescribed for active SLE. Nevertheless, all these correlations, even if statistically significant, were weak and highlight the lack of association between disease activity, damage, and HRQOL. This lack of concordance between the 3 assessments of SLE (disease activity, damage, and HRQOL) underlines that each component measures different aspects of the effect of SLE on the patient and that to fully assess a patient with SLE, we need to measure not only disease activity and damage but also HRQOL. Thus the newly developed and validated disease-specific HRQOL measure, the LupusQoL, provides additional information to the clinical indices of activity and damage.

\section{ACKNOWLEDGMENT}

We acknowledge the assistance of Janet Walker and Julie Gray with database management.

\section{REFERENCES}

1. Johnson A, Gordon C, Palmer R, Bacon P. The prevalence and incidence of systemic lupus erythematosus in Birmingham, England. Relationship to ethnicity and country of birth. Arthritis Rheum 1995;53:551-8.

2. Petri M. Epidemiology of systemic lupus erythematosus. Best Pract Res Clin Rheumatol 2002;16:847-58.

3. Danchenko N, Satia JA, Anthony MS. Epidemiology of systemic lupus erythematosus: a comparison of worldwide disease burden. Lupus 2006;15:308-18.

4. Maddison PJ. Is it SLE? Best Pract Res Clin Rheumatol 2002;16:167-80.

5. Urowitz MB, Gladman DD, Tom BDM, Ibanez D, Farewell VT. Changing patterns in mortality and disease outcomes for patients with systemic lupus erythematosus. J Rheumatol 2008;35:2152-8.

6. McElhone K, Abbott J, Shelmerdine J, Bruce IN, Ahmad Y, Gordon $\mathrm{C}$, et al. Development and validation of a disease-specific health-related quality of life measure, the LupusQoL, for adults with systemic lupus erythematosus. Arthritis Care Res 2007;57:972-9.

7. McElhone K, Abbott J, Teh L-S. Review of health related quality of life (HRQoL) in patients with systemic lupus erythematosus (SLE). Lupus 2006;15:633-43.

8. Tan EM, Cohen AS, Fries SF, Masi AT, McShane DJ, Rothfield NF, et al. The 1982 revised criteria for the classification of systemic lupus erythematosus. Arthritis Rheum 1982;25:1271-7.

9. Hochberg MC. Updating the American College of Rheumatology revised criteria for the classification of systemic lupus erythematosus. Arthritis Rheum 1997;40:1725.
10. UK Office for National Statistics. Census 2001. London. [Internet. Accessed June 30, 2010.] Available from: http://www.statistics.gov.uk/census2001/census2001.asp

11. Hay EM, Bacon PA, Gordon C, Isenberg DA, Maddison P, Snaith ML, et al. The BILAG index: a reliable and valid instrument for measuring clinical disease activity in systemic lupus erythematosus. Q J Med 1993;86:447-58.

12. Isenberg DA, Gordon C. From BILAG to BLIPS - disease activity assessment in lupus past, present and future. Lupus 2000;9:651-4.

13. Gladman DD, Urowitz MB, Goldsmith CH, Fortin P, Ginzler E, Gordon C, et al. The reliability of the Systemic Lupus International Collaborating Clinics/American College of Rheumatology Damage Index in patients with systemic lupus erythematosus. Arthritis Rheum 1997;40:809-13.

14. Stoll T, Stucki G, Malik J, Pyke S, Isenberg DA. Association of the Systemic Lupus International Collaborating Clinics/American College of Rheumatology Damage Index with measures of disease activity and health status in patients with systemic lupus erythematosus. J Rheumatol 1997;24:309-13.

15. Wang B, Gladman DD, Urowitz MB. Fatigue in lupus is not correlated with disease activity. J Rheumatol 1998;25:892-5.

16. Krupp LB, LaRocca NG, Muir J, Steinberg AD. A study of fatigue in systemic lupus erythematosus. J Rheumatol 1990;17:1450-2.

17. Wysenbeek AJ, Leibovici L, Weinberger A, Guedj D. Fatigue in systemic lupus erythematosus, prevalence and relation to disease expression. Br J Rheumatol 1993;32:633-5.

18. Bruce IN, Mak VC, Hallett DC, Gladman DD, Urowitz MB. Factors associated with fatigue in patients with systemic lupus erythematosus. Ann Rheum Dis 1999;58:379-81.

19. Taylor J, Skan J, Erb N, Carruthers D, Bowman S, Gordon C, et al. Lupus patients with fatigue - is there a link with fibromyalgia syndrome? Rheumatology 2000;39:620-3.

20. Gladman DD, Urowitz MB, Ong A, Gough OJ, MacKinnon A. Lack of correlation among 3 outcomes describing SLE: disease activity, damage and quality of life. Clin Exp Rheumatol 1996;14:305-8.

21. Sutcliffe N, Clarke A, Levington C, Frost C, Gordon C, Isenberg D. Associates of health status in patients with systemic lupus erythematosus. J Rheumatol 1999;26:2352-6.

22. Friedman AW, Alarcon GS, McGwin G Jr, Straaton KV, Roseman J, Goel N, et al. Systemic lupus erythematosus in three ethnic groups. IV: Factors associated with self-reported functional outcome in a large cohort study. Arthritis Care Res 1999;12:256-66.

23. Wang C, Mayo NE, Fortin PR. The relationship between health related quality of life and disease activity and damage in systemic lupus erythematosus. J Rheumatol 2001;28:525-32.

24. Rinaldi S, Doria A, Salaffi F, Ermani M, Iaccarino L, Ghirardello A, et al. Health-related quality of life in Italian patients with systemic lupus erythematosus. I. Relationship between physical and mental dimension and impact of age. Rheumatol 2004;43:1574-9.

25. Doria A, Rinaldi S, Ermani M, Salaffi F, Iaccarino L, Ghirardello A, et al. Health-related quality of life in Italian patients with systemic lupus erythematosus. II. Role of clinical, immunological and psychological determinants. Rheumatol 2004;43:1580-6.

26. Jolly M, Utset TO. Can disease specific measures for systemic lupus erythematosus predict patients health related quality of life? Lupus 2004;13:924-6.

27. Cornwell CJ, Schmitt MH. Perceived health status, self-esteem and body image in women with rheumatoid arthritis or systemic lupus erythematosus. Res Nurs Health 1990;13:99-107.

28. Hale ED, Treharne GJ, Norton Y, Lyons AC, Douglas KM, Erb N, et al. 'Concealing the evidence': the importance of appearance concerns for patients with systemic lupus erythematosus. Lupus 2006;15:532-40.

29. Stoll T, Gordon C, Seifert B, Richardson K, Malik J, Bacon PA, et 
al. Consistency and validity of patient administered assessment of quality of life by the MOS SF-36; its association with disease activity and damage in patients with systemic lupus erythematosus. J Rheumatol 1997;24:1608-14.

30. Fortin PR, Abrahamowicz M, Neville C, du Berger R, Fraenkel L, Clarke AE, et al. Impact of disease activity and cumulative damage on the health of lupus patients. Lupus 1998;7:101-7.

31. Lash AA. Quality of life in systemic lupus erythematosus. Appl Nursing Res 1998;11:130-7.

32. Gilboe IM, Kvien TK, Husby G. Health status in systemic lupus erythematosus compared to rheumatoid arthritis and healthy controls. J Rheumatol 1999;26:1694-700.

33. DaCosta D, Dobkin PL, Fitzcharles MA, Fortin PR, Beaulieu A, Zummer M, et al. Determinants of health status in fibromyalgia: A comparative study with systemic lupus erythematosus. J Rheumatol 2000;27:365-72.

34. Gilboe IM, Kvien TK, Husby G. Disease course in systemic lupus erythematosus: changes in health status, disease activity and organ damage after 2 years. J Rheumatol 2001;28:266-74.

35. Alarcon GS, McGwin G Jr, Uribe A, Friedman AW, Roseman JM, Fessler BJ, et al. Systemic lupus erythematosus in a multiethnic lupus cohort (LUMINA). XVII. Predictors of self-reported health related quality of life early in disease course. Arthritis Care Res 2004;51:465-74.

36. Burckhardt CS, Archenholtz B, Bjelle A. Quality of life of women with systemic lupus erythematosus: a comparison with women with rheumatoid arthritis. J Rheumatol 1993;20:977-81.

37. Dobkin PL, Fortin PR, Joseph L, Esdaile JM, Danoff DS, Clarke A. Psychosocial contributors to mental and physical health in patients with systemic lupus erythematosus. Arthritis Care Res 1998;11:23-31.
38. Vu TV, Escalante A. A comparison of the quality of life of patients with systemic lupus erythematosus with and without endstage renal disease. J Rheumatol 1999;26:2595-601.

39. Chambers SA, Allen E, Rahman A, Isenberg D. Damage and mortality in a group of British patients with systemic lupus erythematosus followed up for over 10 years. Rheumatol 2009;48:673-5.

40. Thumboo J, Fong KY, Chan SP, Leong KH, Feng PH, Thio ST, et al. A prospective study of factors affecting quality of life in systemic lupus erythematosus. J Rheumatol 2000;27:1414-20.

41. Curry SL, Levine SB, Corty E, Jones PK, Kurit DM. The impact of systemic lupus erythematosus on women's sexual functioning. J Rheumatol 1994;21:2254-60.

42. Bakewell AB, Higgins RM, Edmunds ME. Does ethnicity influence perceived quality of life of patients on dialysis and following renal transplant? Nephrol Dial Transplant 2001;16:1395-401.

43. Thumboo J, Fong K-Y, Machin D, Chan SP, Soh CH, Leong KH, et al. Quality of life in an urban Asian population: the impact of ethnicity and socio-economic status. Soc Sci Med 2003;56:1761-72.

44. Kumar K, Gordon C, Toescu V, Buckley CD, Horne R, Nightingale PG, et al. Beliefs about medicines in patients with RA and SLE: a comparison between patients of South Asian and White British origin. Rheumatology 2008;47:690-7.

45. Gordon C, Sutcliffe N, Skan J, Stoll T, Isenberg DA. Definition and treatment of lupus flares measured by the BILAG index. Rheumatol 2003;42:1372-9. 